\title{
Influence of maturation on anthropometry and body composition in Japanese junior high school students
}

\author{
Yuko Fukunaga, Yohei Takai', Takaya Yoshimoto, Eiji Fujita, Masayoshi Yamamoto and Hiroaki Kanehisa
}

\begin{abstract}
Background: The purpose of this study was to examine maturity-related differences in anthropometry and body composition in Japanese youth within a single year.

Methods: Two hundred and ten Japanese youth aged from 13 to 13.99 years participated in this study. Their maturity status was assessed using a self-assessment of stage of pubic hair development. Bioelectrical impedance analysis was used to estimate percent body fat and lean body mass (LBM). Muscle thickness of the anterior thigh, posterior lower leg and rectus abdominis muscles were measured by ultrasound.

Results: For boys, height, body weight, and LBM in less mature groups were lower than that in more mature groups. The maturity-related differences were still significant after adjusting for chronological age. On the other hand, muscle thickness values in the lower extremity and abdomen differed among the groups at different stages of pubic hair development, whereas there was no maturity-related difference in the relative values corrected by LBM, except for those thickness values measured at the abdomen. For girls, only the muscle thickness at the anterior thigh and muscle thickness relative to $\mathrm{LBM}^{1 / 3}$ at the posterior lower leg was significantly affected by maturity status, but significant maturity-related difference was not found after adjusting for chronological age.
\end{abstract}

Conclusions: At least for Japanese boys and girls aged 13 years, maturity status affected body size in boys, but not in girls, and the influence of maturation on the muscularity of the lower extremity and trunk muscles is less in both sexes.

Keywords: Adolescence, Body size, Muscle thickness, Pubic hair, Sex

\section{Background}

During adolescence, body size and composition markedly change. These changes are strongly associated with the development of various physical performance characteristics. At the same time, anthropometry and body composition during adolescence are predictors of risk factors for cardiovascular disease, diabetes, and many types of cancers and chronic diseases [1,2] which occur in adults [3-5]. Hence, determining anthropometry and body composition during adolescence would be of interest to those working in both sports sciences and preventive medicine.

\footnotetext{
* Correspondence: y-takai@nifs-k.ac.jp

National Institute of Fitness and Sport in Kanoya, 1 Shiromizu-cho, Kanoya, Kagoshima 8912393, Japan
}

Growth in anthropometry and body composition is influenced by chronological age and maturation. In both boys and girls, increase in chronological age induces growth-related changes in body size (height and body mass) and composition (lean body mass (LBM) and percent body fat (\% Fat)). Maturity-related variation in body size is most marked in an age span of between 13 and 15 years [6]. Individuals who mature earlier have larger body size than those maturing later [3]. These findings indicate that the growth changes measured by anthropometry and body composition involve factors related to both chronological age and maturation and consequently, the interpretation of data concerning individual differences in body size and composition at the corresponding stage is complicated. To clarify the effect of maturation on anthropometry and body composition, 
therefore, it is necessary to examine adolescents within a limited chronological age range in order to reduce the influence of confounding factors on maturity-related difference in those variables.

In general, growth of body height is associated with increases in limb length and tissue mass, regardless of sex $[7,8]$. The timing of the marked change in body height and mass differs between boys and girls. Girls mature earlier than boys [9]. Consequently, the influences of maturation on anthropometry and body composition at the same chronological age could differ between the two sexes. The marked change in muscle size for both boys and girls occurs between 12 and 13 years [10], and its change varies between muscles [11]. Kanehisa et al. [11] demonstrated that sex differences in the cross-sectional areas of plantar and dorsiflexor muscles around the ankle were observed in the chronological age corresponding to puberty. In addition, knee flexor muscle growth predominates over knee extensor growth during puberty [12]. To our knowledge, it is unclear whether maturity level influences the difference the between the growth trends of different muscles.

The purpose of this study was to examine maturityrelated differences in anthropometry and body composition during adolescence. As mentioned above, the rate of muscle growth increases around age 13 years. Hence, we examined the maturity-related differences within a single year in order to reduce the influence of chronological age on those variables in a group of Japanese junior high school students.

\section{Methods}

\section{Subjects}

Four hundred and fifty-two boys $(\mathrm{n}=245)$ and girls $(n=207)$ participated in this study. They were born between 1996 and 1999. The participants were medically screened prior to participation in the experiment. They were free from cardiovascular, metabolic or immunologic disorders and orthopedic abnormality, and did not use any medications that might affect muscle function. The physical characteristics of the subjects are shown in Table 1. Subjects participated in after-school activities such as ball sports (soccer, baseball, volleyball, rubber-ball tennis, and so on), track and field events and drama and art club. The frequency of participation in a week, and duration of their athletic and cultural activities in a day were $5.0 \pm 2.0$ days/week and $2.4 \pm 0.9$ hours/day for boys and $4.9 \pm 2.2$ days/week and $1.9 \pm 1.3$ hours/day for girls, respectively. All participants involved in the sports activities had participated in competitions at regional level.

This study was approved by the ethical committee of the National Institute of Fitness and Sports in Kanoya and was consistent with their requirement for human experimentation. All subjects and their parents were informed of the purpose and procedures of this study and possible risks of the measurements were discussed beforehand. Written informed consent was obtained from each subject and parent.

\section{Experimental design}

All subjects participated in self-assessment of secondary sex characteristics and measurements of anthropometry

Table 1 Physical characteristics for all subjects

\begin{tabular}{|c|c|c|c|c|c|c|}
\hline & \multicolumn{3}{|l|}{ Boys $(n=245)$} & \multicolumn{3}{|l|}{ Girls $(n=207)$} \\
\hline & $\begin{array}{l}12.0 \text { to } 12.99 \text { years } \\
(n=32)\end{array}$ & $\begin{array}{l}13.0 \text { to } 13.99 \text { years } \\
(n=129)\end{array}$ & $\begin{array}{l}14.0 \text { to } 14.99 \text { years } \\
(n=84)\end{array}$ & $\begin{array}{l}12.0 \text { to } 12.99 \text { years } \\
(n=24)\end{array}$ & $\begin{array}{l}13.0 \text { to } 13.99 \text { years } \\
(n=117)\end{array}$ & $\begin{array}{l}14.0 \text { to } 14.99 \text { years } \\
(n=66)\end{array}$ \\
\hline Age (years) & $12.6 \pm 2.2$ & $13.4 \pm 0.3$ & $14.4 \pm 0.3$ & $12.7 \pm 0.2$ & $13.4 \pm 0.3$ & $14.4 \pm 0.2$ \\
\hline Height (cm) & $152.5 \pm 6.3$ & $157.8 \pm 9.4$ & $165 \pm 6.3$ & $152.7 \pm 7.4$ & $154.5 \pm 5.2$ & $155.5 \pm 4.8$ \\
\hline Weight (kg) & $42.0 \pm 6.1$ & $48.2 \pm 9.4$ & $54.5 \pm 7.7$ & $45.0 \pm 8.0$ & $45.4 \pm 5.7$ & $48.1 \pm 5.3$ \\
\hline BMI $\left(\mathrm{kg} / \mathrm{m}^{2}\right)$ & $18.0 \pm 1.9$ & $19.2 \pm 2.6$ & $19.9 \pm 2.0$ & $19.2 \pm 2.5$ & $19.0 \pm 2.0$ & $21.0 \pm 3.4$ \\
\hline$\%$ Fat (\%) & $14.8 \pm 5.8$ & $16.7 \pm 7.9$ & $16.7 \pm 5.4$ & $24.8 \pm 6.8$ & $24.4 \pm 5.5$ & $30.1 \pm 6.3$ \\
\hline LBM (kg) & $35.5 \pm 3.8$ & $39.7 \pm 5.4$ & $45.1 \pm 4.4$ & $33.5 \pm 4.3$ & $34.1 \pm 3.1$ & $34.8 \pm 4.5$ \\
\hline \multicolumn{7}{|c|}{ Number of subjects in each stage of $\mathrm{PH}$} \\
\hline $\mathrm{PH} 1$ & 7 & 11 & 0 & 0 & 6 & 0 \\
\hline $\mathrm{PH} 2$ & 13 & 35 & 5 & 5 & 6 & 0 \\
\hline $\mathrm{PH} 3$ & 3 & 19 & 8 & 3 & 24 & 11 \\
\hline $\mathrm{PH} 4$ & 3 & 24 & 28 & 11 & 42 & 26 \\
\hline $\mathrm{PH} 5$ & 1 & 25 & 20 & 2 & 18 & 16 \\
\hline No answer & 5 & 15 & 23 & 3 & 21 & 13 \\
\hline $\mathrm{PH}$ & $2.2 \pm 1.1$ & $3.1 \pm 1.3$ & $4.0 \pm 0.9$ & $3.5 \pm 1.1$ & $3.6 \pm 1.1$ & $4.1 \pm 0.7$ \\
\hline
\end{tabular}

Values are expressed as mean \pm SD. Age, chronological age; BMI, body mass index;\% Fat, percent body fat; LBM, lean body mass; $\mathrm{PH}$, stage of pubic hair development. 
and body composition as described in the sections below. Two examiners performed each measurement according to sex. Two hundred and two boys (82\%) and 170 girls $(82 \%)$ answered the self-assessment of pubertal stages. The number of subjects at each stage of pubic hair development is shown in Table 1. To assess maturity-related differences in anthropometry and body composition, we re-sampled a cohort within a single year age group, according to sex, who had provided the self-assessment information of pubertal stages. The subsample data consisted of 114 boys and 96 girls aged from 13 to 13.99 years. The distribution of the participants at each of the pubertal stages had no influence of athletic and cultural activities which they regularly performed as extra school curriculums.

\section{Assessment of sexual maturation}

A self-assessment of stage of pubic hair development (PH) based on the criteria of Tanner [13], which was illustrated with black and white, was used to evaluate the secondary sex characteristics. This method has been shown to be in agreement with standard pediatric assessment $[14,15]$. To reduce embarrassment, each subject went into a room by himself to complete the self-assessment anonymously [16]. Once completed, the self-assessment form was put into a box in the room. The stage of $\mathrm{PH}$ consisted of five stages (PH1-5).

\section{Measurements of anthropometry}

Height and weight were measured with standard techniques to the nearest $0.1 \mathrm{~cm}$ and $0.1 \mathrm{~kg}$, respectively. A bioelectrical impedance analyzer with leg-to-leg system (DC-320, Tanita, Japan) was used to estimate \% Fat by using the input variables of body height and sex. The leg-to-leg system has been shown to have validity for estimating body composition $[17,18]$. This method has been also adopted for determining the body composition of children $[19,20]$. Body mass index was calculated from the weight $(\mathrm{kg}) /$ height $\left(\mathrm{m}^{2}\right)$ ratio. LBM was calculated using weight and \% Fat. The circumferences of thigh $\left(\mathrm{C}_{\mathrm{THIGH}}\right)$ and lower leg $\left(\mathrm{C}_{\text {LOWER }}\right)$ were determined using a measuring tape at the same location as that used for ultrasound measurement as described below. As a preliminary, each examiner performed the repeatability test of the muscle thickness measurements on three separate days (>seven days) with three subjects. The intraclass correlation coefficients (ICC) of each examiner were $\geq 0.99$ for one examiner and $\geq 0.92$ for another. The ICC between the examiners was $\geq 0.90$. The coefficients of variance for repeatability test of the circumference measurements of $\mathrm{C}_{\mathrm{THIGH}}$ and $\mathrm{C}_{\mathrm{LOWER}}$ were less than $1 \%$ in each examiner. Measurement error was $<0.6 \mathrm{~cm}$ in each examiner.

\section{Measurements of muscle thicknesses of lower extremity and abdomen}

Muscle thicknesses (MT) at the anterior thigh, posterior lower leg and rectus abdominis muscle were measured using a B-mode ultrasonographic apparatus (Prosound 2, Aloka, Japan) with a linear scanner. During the measurement, the subjects remained in a standing position with their arms and legs relaxed and extended. In accordance with a procedure described in a previous study [21], the measurement sites were precisely located and marked on the anterior surface of the middle of the thigh length (the distance from the greater trochanter of the femur to the articular cleft between the femur and the tibial condyles) and on the posterior surface of the proximal $30 \%$ of the lower leg length (the distance from the articular cleft to the lateral malleolus), at a distance corresponding to 2 to $3 \mathrm{~cm}$ to the right of the umbilicus. A transducer with a $7.5 \mathrm{MHz}$ scanning head was placed perpendicular to the underlying muscle and bone tissues. The scanning head was coated with water-soluble transmission gel, which provided acoustic contact without depressing the dermal surface. The obtained ultrasonographic images were printed out by an echo copier. The muscle thickness was regarded as the distance between the subcutaneous fat-muscle tissue interface and muscle-bone interface for the lower extremity muscles, and muscleabdominal cavity boundary for the abdominal muscles. According to dimensional analysis [7], MT was divided by one-third the power of LBM. The precision and linearity of the image reconstruction have been confirmed elsewhere [22]. The two examiners performed the muscle thickness measurements, according to sex, throughout this study. Showing similarity to the anthropometry measurement, the ICC for the muscle thickness measurement was $\geq 0.97$ for one examiner and 0.91 for the other. The ICC between the two examiners was $\geq 0.89$. The coefficients of variance for the test-retest of the muscle thickness values in each examiner were less than $5 \%$. Measurement error was $<1.2 \mathrm{~mm}$ in each examiner.

\section{Statistical analysis}

Data are presented as mean \pm standard deviation (SD). Spearman's $\rho$ rank correlation coefficient was calculated in order to test the relation between chronological age and stages of pubic hair development in both sexes. To confirm the homoscedasticity in the measured variables, we used the Levene test. For the variables of which the homoscedasticity was accepted, one way factor analysis of variance (ANOVA) was used to test for maturityrelated differences. When appropriate, a Bonferroni post hoc test was used to assess the significance of difference between mean values. If the homoscedasticity was not accepted, the Kruskal Wallis test was used to test significant difference among the stages of pubic hair 
development. When appropriate, the Mann-Whitney test was used to compare among groups. Analysis of covariance (ANCOVA) with chronological age as covariate was used to assess differences among stages of pubic hair development. When appropriate, a Bonferroni post hoc test was used to assess the significance of difference between mean values. The level of significance was set at $P<0.05$. All data analyses were conducted using statistical software (SPSS 19.0 for windows, IBM, Japan).

\section{Results}

\section{Physical characteristics of all subjects}

Descriptive data on physical characteristics of all subjects, each in a single year, is shown in Table 1 . The distribution of population at each stage of pubic hair development indicated that the maturity level was higher in the girls than the boys in the age range from 12 to 14 years (Chi-square test $=31.1, P<0.05$ ). For the girls, therefore, the sample number of the less mature group (PH1 and PH2) was small.

\section{Influence of maturity status on anthropometry and body composition in boys}

Descriptive data on anthropometry and body composition at each stage of pubic hair development is presented in Table 2. Chronological age was lower in PH1 than in PH4 and PH5. The chronological age was significantly related to maturity status (Spearman's $\rho=0.347, P<0.05$ ).

Height, body weight and LBM in less mature groups were lower than that in more mature groups. BMI was lower in PH2 than in PH5. There was no significant difference in \% Fat. PH5 had higher $\mathrm{C}_{\text {THIGH }}$ and $\mathrm{C}_{\text {LOWER }}$ than PH1 and PH2. $\mathrm{C}_{\text {THIGH }}$ in PH4 and $\mathrm{C}_{\text {LOWER }}$ in PH3 and $\mathrm{PH} 4$ were higher than those in $\mathrm{PH} 2$.

Muscle thickness of the anterior thigh in $\mathrm{PH} 2$ was lower than that in PH4 and PH5. Muscle thickness of

Table 2 Maturity-related differences in anthropometry and body composition in adolescent boys

\begin{tabular}{|c|c|c|c|c|c|c|}
\hline & $\begin{array}{l}\text { PH1 } \\
(n=11)\end{array}$ & $\begin{array}{l}\mathrm{PH} 2 \\
(\mathrm{n}=35)\end{array}$ & $\begin{array}{l}\text { PH3 } \\
(n=19)\end{array}$ & $\begin{array}{l}\text { PH4 } \\
(n=24)\end{array}$ & $\begin{array}{l}\text { PH5 } \\
(n=25)\end{array}$ & $\begin{array}{l}\text { Post hoc test } \\
(P<0.05)\end{array}$ \\
\hline Age (years) & $13.2 \pm 0.2$ & $13.4 \pm 0.2$ & $13.4 \pm 0.3$ & $13.5 \pm 0.2$ & $13.5 \pm 0.3$ & $\mathrm{PH}<\mathrm{PH} 4, \mathrm{PH} 5$ \\
\hline \multirow[t]{3}{*}{ Height (cm) } & $147.4 \pm 8.8$ & $151.4 \pm 6.4$ & $157.1 \pm 7.4$ & $162.4 \pm 4.7$ & $165.4 \pm 4.7$ & $\mathrm{PH} 1, \mathrm{PH} 2<\mathrm{PH} 3-5$ \\
\hline & & & & & & $\mathrm{PH} 3<\mathrm{PH} 4-5$ \\
\hline & & & & & & $\mathrm{PH} 4<\mathrm{PH} 5$ \\
\hline \multirow[t]{4}{*}{ Weight (kg) } & $41.0 \pm 10.0$ & $41.5 \pm 6.7$ & $48.3 \pm 8.9$ & $51.8 \pm 7.9$ & $54.5 \pm 4.8$ & $\mathrm{PH} 1, \mathrm{PH} 2<\mathrm{PH} 4, \mathrm{PH} 5$ \\
\hline & & & & & & $\mathrm{PH} 2<\mathrm{PH} 3$ \\
\hline & & & & & & $\mathrm{PH} 3<\mathrm{PH} 5$ \\
\hline & & & & & & $\mathrm{PH} 2<5$ \\
\hline BMI $\left(\mathrm{kg} / \mathrm{m}^{2}\right)$ & $18.77 \pm 2.7$ & $18.0 \pm 2.2$ & $19.5 \pm 3.3$ & $19.6 \pm 2.5$ & $20.0 \pm 1.8$ & \\
\hline$\%$ Fat $(\%)$ & $16.0 \pm 6.7$ & $13.9 \pm 6.5$ & $17.7 \pm 11.2$ & $17.0 \pm 8.0$ & $18.3 \pm 5.7$ & \\
\hline \multirow[t]{2}{*}{$\operatorname{LBM}(\mathrm{kg})$} & $33.9 \pm 5.0$ & $35.4 \pm 4.0$ & $39.0 \pm 4.6$ & $42.4 \pm 3.2$ & $44.4 \pm 3.1$ & $\mathrm{PH} 1, \mathrm{PH} 2<\mathrm{PH} 3-5$ \\
\hline & & & & & & $\mathrm{PH} 3<\mathrm{PH} 5$ \\
\hline \multirow[t]{2}{*}{$\mathrm{C}_{\mathrm{THIGH}}(\mathrm{cm})$} & $43.1 \pm 5.3$ & $42.3 \pm 3.7$ & $45.4 \pm 4.8$ & $46.7 \pm 4.2$ & $47.4 \pm 2.5$ & $\mathrm{PH} 1, \mathrm{PH} 2<\mathrm{PH} 3-5$ \\
\hline & & & & & & $\mathrm{PH} 1<\mathrm{PH} 5$ \\
\hline \multirow[t]{2}{*}{ CLOWER $(\mathrm{cm})$} & $32.0 \pm 3.6$ & $31.5 \pm 2.5$ & $33.8 \pm 2.8$ & $34.5 \pm 2.2$ & $34.9 \pm 1.8$ & $\mathrm{PH} 1, \mathrm{PH} 2<\mathrm{PH} 5$ \\
\hline & & & & & & $\mathrm{PH} 2<\mathrm{PH} 3, \mathrm{PH} 4$ \\
\hline \multicolumn{7}{|l|}{ Muscle thickness (cm) } \\
\hline Anterior thigh & $4.3 \pm 0.6$ & $4.2 \pm 0.6$ & $4.5 \pm 0.5$ & $4.8 \pm 0.4$ & $4.7 \pm 0.4$ & $\mathrm{PH} 2<\mathrm{PH} 4, \mathrm{PH} 5$ \\
\hline \multirow[t]{2}{*}{ Posterior of lower leg } & $5.9 \pm 0.6$ & $5.8 \pm 0.4$ & $6.4 \pm 0.5$ & $6.4 \pm 0.4$ & $6.5 \pm 0.5$ & $\mathrm{PH} 1, \mathrm{PH} 2<\mathrm{PH} 5$ \\
\hline & & & & & & $\mathrm{PH} 2<\mathrm{PH} 3, \mathrm{PH} 4$ \\
\hline \multirow[t]{2}{*}{ Rectus abdominis } & $1.0 \pm 0.2$ & $0.9 \pm 0.1$ & $1.1 \pm 0.2$ & $1.2 \pm 0.2$ & $1.3 \pm 0.2$ & $\mathrm{PH} 1-3<\mathrm{PH} 5$ \\
\hline & & & & & & $\mathrm{PH} 2<\mathrm{PH} 4$ \\
\hline \multicolumn{7}{|c|}{ Muscle thickness per $\mathrm{LBM}^{1 / 3}\left(\mathrm{~cm} / \mathrm{kg}^{1 / 3}\right)$} \\
\hline Anterior of lower leg & $1.31 \pm 0.13$ & $1.27 \pm 0.16$ & $1.32 \pm 0.16$ & $1.37 \pm 0.10$ & $1.32 \pm 0.21$ & \\
\hline Posterior of lower leg & $1.82 \pm 0.12$ & $177 \pm 0.10$ & $1.89 \pm 0.14$ & $1.83 \pm 0.09$ & $1.84 \pm 0.12$ & \\
\hline Rectus abdominis & $0.31 \pm 0.04$ & $0.29 \pm 0.04$ & $0.32 \pm 0.04$ & $0.33 \pm 0.04$ & $0.36 \pm 0.06$ & $\mathrm{PH} 2<\mathrm{PH} 4, \mathrm{PH} 5$ \\
\hline
\end{tabular}


the posterior lower leg was lower in $\mathrm{PH} 1$ and $\mathrm{PH} 2$ than in $\mathrm{PH} 5$, and in $\mathrm{PH} 2$ than in $\mathrm{PH} 3$ and $\mathrm{PH} 4$. Rectus abdominis muscle thickness was lower in $\mathrm{PH} 1$ to $\mathrm{PH} 3$ than in $\mathrm{PH} 5$, and in $\mathrm{PH} 2$ than in $\mathrm{PH} 4$. Muscle thickness relative to $\mathrm{LBM}^{1 / 3}$ in the rectus abdominis muscle was lower in $\mathrm{PH} 2$ than in PH4 and PH5. There was no maturityrelated difference in the muscle thickness of the anterior thigh and posterior lower leg. As a result of the ANCOVA with chronological age as covariate (Table 3), significant maturity-related differences were still found to be similar to those in Table 2 .

\section{Influence of maturity on anthropometry and body composition in girls}

Maturity-related differences in the anthropometry and body composition in adolescent girls are shown in Table 4 . Only $\mathrm{C}_{\mathrm{LOWER}}$, muscle thickness of the anterior thigh and posterior lower leg relative to $\mathrm{LBM}^{1 / 3}$ showed a significant effect of maturity status. Chronological age was not significantly related to maturity status (Spearman's $\rho=0.095$ ).
The results of ANCOVA with chronological age as covariate (Table 5) showed there was no significant maturity-related differences in these variables except for $\mathrm{C}_{\text {LOWER }}(\mathrm{PH} 2<\mathrm{PH} 4)$.

\section{Discussion}

The main findings obtained here are that, at least in 13 year-olds, 1) maturity status affected body size (height and weight) in boys, but not in girls, and 2) the muscularity of the lower extremity and trunk was less influenced by maturity status. The mean values of the body height and mass for the subjects examined here were similar to those reported by Kobayashi et al. [23] and Suwa et al. [24], and were within the normative data for Japanese youth at the same age (Ministry of Education, Culture, Sports, Science and Technology in Japan, 2009). Hence, the data presented here can be considered to be representative for Japanese youth. Before discussing the current results, we should comment that direct comparison between sexes on the measured variables is not

Table 3 Physical characteristics after adjustment for chronological age in adolescent boys

\begin{tabular}{|c|c|c|c|c|c|c|}
\hline & $\begin{array}{l}\text { PH1 } \\
(n=11)\end{array}$ & $\begin{array}{l}\mathrm{PH} 2 \\
(\mathrm{n}=35)\end{array}$ & $\begin{array}{l}\text { PH3 } \\
(n=19)\end{array}$ & $\begin{array}{l}\text { PH4 } \\
(n=24)\end{array}$ & $\begin{array}{l}\text { PH5 } \\
(n=25)\end{array}$ & Post hoc test $(P<0.05)$ \\
\hline \multirow[t]{2}{*}{ Height (cm) } & $148.4 \pm 1.9$ & $151.7 \pm 1.0$ & $157.2 \pm 1.4$ & $162.0 \pm 1.3$ & $164.8 \pm 1.2$ & $\mathrm{PH} 1, \mathrm{PH} 2<\mathrm{PH} 3-5$ \\
\hline & & & & & & $\mathrm{PH} 3<\mathrm{PH} 5$ \\
\hline \multirow[t]{3}{*}{ Weight (kg) } & $41.6 \pm 2.3$ & $41.6 \pm 1.3$ & $48.3 \pm 1.7$ & $51.5 \pm 1.5$ & $54.3 \pm 1.5$ & $\mathrm{PH} 1, \mathrm{PH} 2<\mathrm{PH} 4, \mathrm{PH} 5$ \\
\hline & & & & & & $\mathrm{PH} 2<\mathrm{PH} 3$ \\
\hline & & & & & & $\mathrm{PH} 2<\mathrm{PH} 5$ \\
\hline $\mathrm{BMI}\left(\mathrm{kg} / \mathrm{m}^{2}\right)$ & $18.6 \pm 0.8$ & $18.0 \pm 0.4$ & $19.5 \pm 0.6$ & $19.6 \pm 0.5$ & $20.0 \pm 0.5$ & \\
\hline$\%$ Fat (\%) & $15.4 \pm 2.4$ & $13.7 \pm 0.6$ & $17.7 \pm 1.8$ & $17.2 \pm 1.6$ & $18.6 \pm 1.6$ & \\
\hline \multirow[t]{3}{*}{ LBM (kg) } & $34.7 \pm 1.2$ & $35.7 \pm 0.6$ & $39.1 \pm 0.9$ & $42.1 \pm 0.8$ & $44.0 \pm 0.8$ & $\mathrm{PH} 1, \mathrm{PH} 2<\mathrm{PH} 3-5$ \\
\hline & & & & & & $\mathrm{PH} 3<\mathrm{PH} 5$ \\
\hline & & & & & & $\mathrm{PH} 2<\mathrm{PH} 4, \mathrm{PH} 5$ \\
\hline $\mathrm{C}_{\mathrm{THIGH}}(\mathrm{cm})$ & $43.3 \pm 1.2$ & $42.4 \pm 0.7$ & $45.4 \pm 0.9$ & $46.7 \pm 0.8$ & $47.4 \pm 0.8$ & \\
\hline \multirow[t]{2}{*}{ CLOWER $(\mathrm{cm})$} & $32.1 \pm 0.8$ & $31.6 \pm 0.4$ & $33.8 \pm 0.6$ & $34.4 \pm 0.5$ & $34.8 \pm 0.5$ & $\mathrm{PH} 1<\mathrm{PH} 5$ \\
\hline & & & & & & $\mathrm{PH} 2<\mathrm{PH} 3-5$ \\
\hline \multicolumn{7}{|l|}{ Muscle thickness (cm) } \\
\hline Anterior thigh & $4.3 \pm 0.2$ & $4.2 \pm 0.1$ & $4.5 \pm 0.1$ & $4.8 \pm 0.1$ & $4.7 \pm 0.1$ & $\mathrm{PH} 2<\mathrm{PH} 4, \mathrm{PH} 5$ \\
\hline \multirow[t]{2}{*}{ Posterior of lower leg } & $6.0 \pm 0.1$ & $5.8 \pm 0.1$ & $6.4 \pm 0.1$ & $6.4 \pm 0.1$ & $6.5 \pm 0.1$ & $\mathrm{PH} 1, \mathrm{PH} 2<\mathrm{PH} 5$ \\
\hline & & & & & & $\mathrm{PH} 2<\mathrm{PH} 3, \mathrm{PH} 4$ \\
\hline \multirow[t]{2}{*}{ Rectus abdominis } & $1.1 \pm 0.1$ & $1.0 \pm 0.0$ & $1.1 \pm 0.0$ & $1.2 \pm 0.0$ & $1.3 \pm 0.0$ & $\mathrm{PH} 1-3<\mathrm{PH} 5$ \\
\hline & & & & & & $\mathrm{PH} 2<\mathrm{PH} 4$ \\
\hline \multicolumn{7}{|c|}{ Muscle thickness per $\operatorname{LBM}^{1 / 3}\left(\mathrm{~cm} / \mathrm{kg}^{1 / 3}\right)$} \\
\hline Anterior of lower leg & $1.31 \pm 0.04$ & $1.27 \pm 0.02$ & $1.32 \pm 0.03$ & $1.37 \pm 0.03$ & $1.32 \pm 0.03$ & \\
\hline Posterior of lower leg & $1.51 \pm 0.05$ & $1.41 \pm 0.03$ & $1.48 \pm 0.04$ & $1.48 \pm 0.03$ & $1.49 \pm 0.03$ & \\
\hline Rectus abdominis & $0.32 \pm 0.01$ & $0.29 \pm 0.01$ & $0.32 \pm 0.01$ & $0.33 \pm 0.01$ & $0.35 \pm 0.01$ & $\mathrm{PH} 2<\mathrm{PH} 4, \mathrm{PH} 5$ \\
\hline
\end{tabular}


Table 4 Maturity-related differences in anthropometry and body composition in adolescent girls

\begin{tabular}{|c|c|c|c|c|c|c|}
\hline & $\begin{array}{l}\text { PH1 } \\
(n=6)\end{array}$ & $\begin{array}{l}\mathrm{PH} 2 \\
(n=6)\end{array}$ & $\begin{array}{l}\mathrm{PH} 3 \\
(\mathrm{n}=24)\end{array}$ & $\begin{array}{l}\text { PH4 } \\
(n=42)\end{array}$ & $\begin{array}{l}\text { PH5 } \\
(n=18)\end{array}$ & $\begin{array}{l}\text { Post hoc test } \\
(P<0.05)\end{array}$ \\
\hline Age (years) & $13.1 \pm 0.1$ & $13.4 \pm 0.2$ & $13.4 \pm 0.2$ & $13.4 \pm 0.3$ & $13.4 \pm 0.3$ & \\
\hline Height (cm) & $149.6 \pm 4.3$ & $154.7 \pm 4.3$ & $152.9 \pm 5.0$ & $155.9 \pm 5.0$ & $155.44 \pm 3.8$ & \\
\hline Weight (kg) & $42.1 \pm 3.7$ & $42.2 \pm 5.8$ & $43.5 \pm 7.3$ & $47.1 \pm 5.4$ & $47.6 \pm 5.1$ & \\
\hline $\mathrm{BMI}\left(\mathrm{kg} / \mathrm{m}^{2}\right)$ & $18.8 \pm 1.5$ & $17.6 \pm 1.9$ & $18.6 \pm 2.7$ & $19.4 \pm 1.8$ & $19.7 \pm 2.1$ & \\
\hline$\%$ Fat (\%) & $24.2 \pm 7.2$ & $21.1 \pm 5.5$ & $22.6 \pm 6.8$ & $24.9 \pm 4.7$ & $26.3 \pm 4.8$ & \\
\hline LBM (kg) & $31.8 \pm 2.3$ & $33.1 \pm 3.2$ & $33.2 \pm 3.1$ & $35.2 \pm 3.4$ & $34.8 \pm 2.1$ & \\
\hline $\mathrm{C}_{\mathrm{THIGH}}(\mathrm{cm})$ & $43.3 \pm 1.6$ & $42.1 \pm 2.7$ & $43.9 \pm 4.2$ & $45.9 \pm 3.4$ & $46.3 \pm 3.4$ & \\
\hline \multirow[t]{2}{*}{$C_{\text {LOWER }}(\mathrm{cm})$} & $31.8 \pm 0.9$ & $30.6 \pm 1.5$ & $31.8 \pm 2.5$ & $33.3 \pm 2.0$ & $33.0 \pm 1.9$ & $\mathrm{PH} 2<\mathrm{PH} 4, \mathrm{PH} 5$ \\
\hline & & & & & & $\mathrm{PH} 3<\mathrm{PH} 4$ \\
\hline \multicolumn{7}{|l|}{ Muscle thickness $(\mathrm{cm})$} \\
\hline \multirow[t]{2}{*}{ Anterior thigh } & $4.5 \pm 0.3$ & $3.9 \pm 0.3$ & $4.3 \pm 0.5$ & $4.5 \pm 0.5$ & $4.6 \pm 0.4$ & $\mathrm{PH} 1>\mathrm{PH} 2$ \\
\hline & & & & & & $\mathrm{PH} 2<\mathrm{PH} 4, \mathrm{PH} 5$ \\
\hline Posterior of lower leg & $5.9 \pm 0.3$ & $5.6 \pm 0.7$ & $5.8 \pm 0.6$ & $6.0 \pm 0.4$ & $6.0 \pm 0.4$ & \\
\hline Rectus abdominis & $1.0 \pm 0.2$ & $1.0 \pm 0.2$ & $1.0 \pm 0.2$ & $1.0 \pm 0.1$ & $1.0 \pm 0.1$ & \\
\hline \multicolumn{7}{|c|}{ Muscle thickness per $\operatorname{LBM}^{1 / 3}\left(\mathrm{~cm} / \mathrm{kg}^{1 / 3}\right)$} \\
\hline Anterior of lower leg & $1.43 \pm 0.12$ & $1.22 \pm 0.10$ & $1.35 \pm 0.13$ & $1.37 \pm 0.14$ & $1.40 \pm 0.13$ & \\
\hline Posterior of lower leg & $1.86 \pm 0.05$ & $1.73 \pm 0.17$ & $1.81 \pm 0.14$ & $1.84 \pm 0.10$ & $1.83 \pm 0.09$ & $\mathrm{PH} 2<\mathrm{PH} 5$ \\
\hline Rectus abdominis & $0.30 \pm 0.05$ & $0.31 \pm 0.07$ & $0.31 \pm 0.05$ & $0.32 \pm 0.04$ & $0.31 \pm 0.04$ & \\
\hline
\end{tabular}

Values are expressed as mean \pm SD. Age, chronological age; BMI, body mass index; \% Fat, percent body fat; LBM, lean body mass; $C_{\mathrm{THIGH}}$, circumference of thigh; $C_{\text {LOWER, }}$ circumference of lower leg; PH, stage of pubic hair development.

Table 5 Physical characteristics after adjustment for chronological age in adolescent girls

\begin{tabular}{|c|c|c|c|c|c|c|}
\hline & $\begin{array}{l}\text { PH1 } \\
(n=6)\end{array}$ & $\begin{array}{l}\mathrm{PH} 2 \\
(n=6)\end{array}$ & $\begin{array}{l}\mathrm{PH} 3 \\
(\mathrm{n}=24)\end{array}$ & $\begin{array}{l}\text { PH4 } \\
(n=42)\end{array}$ & $\begin{array}{l}\text { PH5 } \\
(n=18)\end{array}$ & $\begin{array}{l}\text { Post hoc test } \\
(P<0.05)\end{array}$ \\
\hline Height $(\mathrm{cm})$ & $151.0 \pm 1.9$ & $154.7 \pm 1.9$ & $152.8 \pm 0.9$ & $155.8 \pm 0.7$ & $155.5 \pm 1.1$ & \\
\hline Weight (kg) & $43.5 \pm 2.4$ & $42.2 \pm 2.3$ & $43.4 \pm 1.2$ & $47.0 \pm 0.9$ & $47.7 \pm 1.3$ & \\
\hline $\mathrm{BMI}\left(\mathrm{kg} / \mathrm{m}^{2}\right)$ & $19.1 \pm 0.9$ & $17.6 \pm 0.8$ & $18.5 \pm 0.4$ & $19.3 \pm 0.3$ & $19.7 \pm 0.5$ & \\
\hline \% Fat (\%) & $24.4 \pm 2.4$ & $21.1 \pm 2.3$ & $22.6 \pm 1.1$ & $24.9 \pm 0.9$ & $26.4 \pm 1.3$ & \\
\hline LBM (kg) & $32.6 \pm 1.3$ & $33.2 \pm 1.2$ & $33.2 \pm 0.6$ & $35.1 \pm 0.5$ & $34.9 \pm 0.7$ & \\
\hline$C_{T H I G H}(\mathrm{~cm})$ & $44.1 \pm 1.5$ & $42.1 \pm 1.4$ & $43.8 \pm 0.7$ & $45.8 \pm 0.5$ & $46.4 \pm 0.8$ & \\
\hline$C_{\text {LOWER }}(\mathrm{cm})$ & $32.2 \pm 0.9$ & $30.6 \pm 0.8$ & $31.8 \pm 0.4$ & $33.2 \pm 0.3$ & $33.0 \pm 0.5$ & $\mathrm{PH} 2<\mathrm{PH} 4$ \\
\hline \multicolumn{7}{|l|}{ Muscle thickness (cm) } \\
\hline Anterior thigh & $4.6 \pm 0.2$ & $3.9 \pm 0.2$ & $4.3 \pm 0.1$ & $4.5 \pm 0.1$ & $4.6 \pm 0.1$ & \\
\hline Posterior of lower leg & $6.0 \pm 0.2$ & $5.6 \pm 0.2$ & $5.8 \pm 0.1$ & $6.0 \pm 0.1$ & $6.0 \pm 0.1$ & \\
\hline Rectus abdominis & $1.0 \pm 0.1$ & $1.0 \pm 0.1$ & $1.0 \pm 0.0$ & $1.0 \pm 0.0$ & $1.0 \pm 0.0$ & \\
\hline \multicolumn{7}{|c|}{ Muscle thickness per $\operatorname{LBM}^{1 / 3}\left(\mathrm{~cm} / \mathrm{kg}^{1 / 3}\right)$} \\
\hline Anterior of lower leg & $1.44 \pm 0.05$ & $1.22 \pm 0.05$ & $1.35 \pm 0.03$ & $1.37 \pm 0.02$ & $1.41 \pm 0.03$ & \\
\hline Posterior of lower leg & $1.88 \pm 0.05$ & $1.73 \pm 0.05$ & $1.81 \pm 0.02$ & $1.83 \pm 0.02$ & $1.84 \pm 0.03$ & \\
\hline Rectus abdominis & $0.30 \pm 0.02$ & $0.32 \pm 0.02$ & $0.31 \pm 0.01$ & $0.32 \pm 0.01$ & $0.31 \pm 0.01$ & \\
\hline
\end{tabular}


presented. It is known that there is a sex difference in hormonal secretions (for example, estradiol, insulin-like growth hormone, growth hormone and testosterone) even at the same chronological age or pubertal stages [25]. Unfortunately, we have no information on this subject, so we focus the content of the discussion on the maturityrelated differences in anthropometry and body composition each for boys and girls.

In boys, body height and mass were lower in less mature groups (PH1-2) than more mature groups (PH4-5). According to descriptive data of Japanese boys [23,24,26], the age at peak height growth velocity is 12.84 to 13.65 years, and the height at that time is 153.4 to $156.3 \mathrm{~cm}$. As shown in Table 2, those values are observed between the stage of PH2 and PH3. This implies that this current study was examining boys at around the onset of growth spurt. The maturity-related differences in body height and mass were still significant even when chronological age was adjusted for. Considering that testosterone level is associated with body size (height and lean body mass) and the stage of pubic hair development [16], the current results indicate that the body size for 13 year-old boys may be affected by maturity status. Furthermore, lean body mass was also affected by maturity status. LBM was strongly associated with height and weight in this study (unpresented data), and no maturity-related difference in \% Fat was found. Hence, maturity-related differences in LBM may be attributed to those in body size.

Contrary to results for boys, no maturity-related differences in height and weight were found in girls. This result indicates that, at least in 13 year-olds, the growth of body size of girls is less affected by maturation. This seems to be due to earlier maturation in females than in males. Age at peak height velocity is approximately 11 years in Japanese girls, and the height at this point is $141 \mathrm{~cm}$ [24]. For the girls examined here, the mean height value was, on average, 149.6 to $155.4 \mathrm{~cm}$ across the stages of pubic hair development. The chronological age of the current subjects was, on average, 13.4 years. The ages of girls in this study were gone by approximately two years from the age at peak height velocity in Japanese girls. The current results also showed that the number of subjects in the less mature groups was small in girls (Table 1). Considering these observations, it is reasonable to say that pubertal onset has already occurred in most of the girls. This could cause the lack of maturity-related difference in the current study.

For boys, the maturity-related differences in lower extremity and trunk muscles were similar to those in body size and lean body mass. Growth in height is accompanied by quantitative increases in other tissues $[7,8]$. On the other hand, when the muscle thickness of the lower extremity and abdomen was corrected by $\mathrm{LBM}^{1 / 3}$, the sites where the maturity-related differences in muscle thickness were found were limited to the rectus abdominis for the boys and posterior lower leg for the girls. This result indicates that muscle growth is proportional to that of body size, and the influence of maturation on muscle growth is less in both sexes.

We should mention the limitations of the present study. We analyzed data obtained from the subjects regardless of the after-school activities in which the subjects participated. Hence, there is a possibility that the current findings might have been influenced by differences in after-school sports events or culture activities. In the subjects examined here, however, there were no obvious event-related differences in the stage of $\mathrm{PH}$. Moore et al. [27] reported that the stage of PH did not show event-related differences compared with inactive children. Furthermore, it has been shown that regular participation in sport training during puberty does not influence body size attained, growth rate, and the timing and progression of somatic, sexual and skeletal maturation in boys and girls [28,29]. Considering these findings, we can say that the influence of event-related differences on the current results might not be very great. Another potential factor is the limited evaluation of secondary sex characteristics. The evaluation of secondary sex characteristics used in the current study gives no information on when the boy or girl had entered a stage, or for how long he or she had been at a certain developmental stage. Unfortunately, we have no physiological data relevant to maturation and further investigation is needed to clarify these points.

In adolescents, anthropometry and body composition are predictors of risk factors for some chronic diseases such as cardiovascular disease, diabetes, and many types of cancers $[1,2]$. The current findings were obtained from normal Japanese youth and revealed the extent that maturation influences anthropometry and body composition. This may contribute to enabling us to discern specific abnormal growth in anthropometry and body composition, which can be associated with increased risk of some chronic diseases.

\section{Conclusions}

At least for Japanese boys and girls aged 13 years, maturity status affected body size of boys, but not of girls, but there is less influence of maturation on the muscularity of the lower extremity and trunk muscles in both sexes.

\section{Abbreviations}

ANOVA: Analysis of variance; ANCOVA: Analysis of covariance; BMI: Body mass index; $C_{\text {LowER: }}$ : Circumference of the lower leg; $C_{T H H G H}$ : Circumference of the thigh; \% Fat: Percent body fat; ICC: Intraclass correlation coefficient; LBM: Lean body mass; MT: Muscle thickness; PH: Pubic hair development.

\section{Competing interests}

We do not have any conflict of interest. 


\section{Authors' contributions}

YF carried out the anthropometric measurement, performed the statistical analysis and drafted the manuscript. YT conceived of the study, and participated in its design and coordination and helped to draft the manuscript. TY and EF carried out the anthropometric measurement and helped to perform the statistical analysis. MY and HK supervised the survey, participated in the design of the study and performed the statistical analysis. All authors read and approved the final manuscript.

\section{Acknowledgements}

This work is supported by the Grant-in-Aid for Scientific Research (B) (22300218). The authors thank the teachers of the pilot study schools in Kagoshima, and students of National Institute of Fitness and Sports in Kanoya for their contributions.

Received: 7 August 2012 Accepted: 22 February 2013

Published: 12 March 2013

\section{References}

1. Dietz WH: Childhood weight affects adult morbidity and mortality. J Nutr 1998, 128:411S-414S.

2. Goran MI, Ball GD, Cruz ML: Obesity and risk of type 2 diabetes and cardiovascular disease in children and adolescents. $J$ Clin Endocrinol Metab 2003, 88:1417-1427.

3. Guo SS, Chumlea WC, Roche AF, Siervogel RM: Age- and maturity-related changes in body composition during adolescence into adulthood: the Fels longitudinal study. Int J Obesity 1997, 21:1167-1175.

4. Katzmarzyk PT, Perusse L, Malina RM, Bergeron J, Despres JP, Bouchard C: Stability of indicators of the metabolic syndrome from childhood and adolescence to young adulthood: the Quebec family study. J Clin Epidemiol 2001, 54:190-195.

5. Janssen I, Katzmarzyk PT, Srinivasan SR, Chen W, Malina RM, Bouchard C, Berenson GS: Utility of childhood BMI in the prediction of adulthood disease: comparison of national and international references. Obes Res 2005, 13:1106-1115.

6. Malina RM, Bouchard C, Bar-Or O: Growth, Maturation, and Physical Activity. Champaign, IL: Human Kinetics; 2004.

7. Asmussen $\mathrm{E}$, Heeboll-Nielsen $\mathrm{K}$ : A dimensional analysis of physical performance and growth in boys. J Appl Physiol 1955, 7:593-603.

8. Asmussen $E_{1}$ Heeboll-Nielsen K: Physical performance and growth in children: influence of sex, age and intelligence. J Appl Physio/ 1956, 8:371-380.

9. Hagg U, Taranger J: Height and height velocity in early, average and late maturers followed to the age of 25: a prospective longitudinal study of Swedish urban children from birth to adulthood. Ann Hum Biol 1991, 18:47-56

10. Tanner JM, Hughes PC, Whitehouse RH: Radiographically determined widths of bone muscle and fat in the upper arm and calf from age 3 to 18 years. Ann Hum Biol 1981, 8:495-517.

11. Kanehisa $H$, Yata $H$, lkegawa $S$, Fukunaga $T$ : A cross-sectional study of the size and strength of the lower leg muscles during growth. Eur J Appl Physiol Occup Physiol 1995, 72:150-156.

12. Kanehisa H, Ikegawa S, Tsunoda N, Fukunaga T: Strength and crosssectional areas of reciprocal muscle groups in the upper arm and thigh during adolescence. Int J Sports Med 1995, 16:54-60.

13. Tanner JM: Growth at adolescence. 2nd edition. Oxford: Blackwell Scientific Publications; 1962

14. Duke PM, Litt IF, Gross RT: Adolescents' self-assessment of sexual maturation. Pediatrics 1980, 66:918-920

15. Chan NP, Sung RY, Kong AP, Goggins WB, So HK, Nelson EA: Reliability of pubertal self-assessment in Hong Kong Chinese children. J Paediatr Child Health 2008, 44:353-358.

16. Gurd B, Klentrou P: Physical and pubertal development in young male gymnasts. J Appl Physiol 2003, 95:1011-1015.

17. Nunez C, Gallagher D, Visser M, Pi-Sunyer FX, Wang Z, Heymsfield SB: Bioimpedance analysis: evaluation of leg-to-leg system based on pressure contact footpad electrodes. Med Sci Sports Exerc 1997, 29:524-531.

18. Jebb SA, Cole TJ, Doman D, Murgatroyd PR, Prentice AM: Evaluation of the novel Tanita body-fat analyzer to measure body composition by comparison with a four-compartment model. Br J Nutr 2000, 83:115-122.
19. Sung RY, Lau P, Yu CW, Lam PK, Nelson EA: Measurement of body fat using leg-to-leg bioimpedance. Arch Dis Child 2001, 85:263-267.

20. Sampei MA, Novo NF, Juliano Y, Sigulem DM: Anthropometry and body composition in ethnic Japanese and Caucasian adolescent boys. Pediatr Int 2008, 50:679-686.

21. Abe T, Kondo M, Kawakami $Y$, Fukunaga T: Prediction equations for body composition of Japanese adults by B-mode ultrasound. Am J Hum Biol 1994, 6:161-170.

22. Kawakami Y, Abe T, Fukunaga T: Muscle-fiber pennation angles are greater in hypertrophied than in normal muscles. J Appl Physiol 1993, 74:2740-2744

23. Kobayashi K, Kitamura K, Miura M, Sodeyama H, Murase Y, Miyashita M Matsui $\mathrm{H}$ : Aerobic power as related to body growth and training in Japanese boys: a longitudinal study. J Appl Physiol 1978, 44:666-672.

24. Suwa S, Tachibana K, Maesaka H, Tanaka T, Yokoya S: Longitudinal standards for height and height velocity for Japanese children from birth to maturity. Clin Pediatric Endocrinol 1992, 1:5-13.

25. Argente J, Evain-Brion D, Munoz-Villa A, Garnier P, Hernandez M, Donnadieu M: Relationship of plasma growth hormone-releasing hormone levels to pubertal changes. J Clin Endocrinol Metab 1986, 63:680-682.

26. Nariyama K, Hauspie RC, Mino T: Longitudinal growth study of male Japanese junior high school athletes. Am J Hum Biol 2001, 13:356-364.

27. Moore SA, Moore M, Klentrou P, Sullivan P, Falk B: Maturity status in male child and adolescent athletes. J Sports Med Phys Fitness 2010, 50:486-493.

28. Malina RM, Bielicki T: Retrospective longitudinal growth study of boys and girls active in sport. Acta Paediatr 1996, 85:570-576.

29. Malina RM, Woynarowska B, Bielicki T, Beunen G, Eweld D, Geithner CA, Huang YC, Rogers DM: Prospective and retrospective longitudinal studies of the growth, maturation, and fitness of Polish youth active in sport. Int J Sports Med 1997, 18(Suppl 3):S179-S185.

doi:10.1186/1880-6805-32-5

Cite this article as: Fukunaga et al:: Influence of maturation on anthropometry and body composition in Japanese junior high school students. Journal of Physiological Anthropology 2013 32:5.

\section{Submit your next manuscript to BioMed Central and take full advantage of:}

- Convenient online submission

- Thorough peer review

- No space constraints or color figure charges

- Immediate publication on acceptance

- Inclusion in PubMed, CAS, Scopus and Google Scholar

- Research which is freely available for redistribution 